\title{
Halobacterium Expression System for Production of Full-Length Plasmodium falciparum Circumsporozoite Protein
}

\author{
Chapter · January 2016 \\ DOI: 10.1007/978-3-319-13521-2_25
}

\section{CITATIONS}

2

6 authors, including:

Wolf T Pecher

University of Baltimore

17 PUBLICATIONS 112 CITATIONS

SEE PROFILE

\section{Ram Karan}

University System of Maryland

21 PUBLICATIONS 367 CITATIONS

SEE PROFILE
READS

120

\section{Priya Dassarma}

University of Maryland, Baltimore, School of ...

58 PUBLICATIONS 747 CITATIONS

SEE PROFILE

\section{Shiladitya Dassarma}

University of Maryland, Baltimore

153 PUBLICATIONS 4,315 CITATIONS

SEE PROFILE

Some of the authors of this publication are also working on these related projects: 


\title{
Chapter 25 \\ Halobacterium Expression System for Production of Full-Length Plasmodium falciparum Circumsporozoite Protein
}

\author{
Wolf T. Pecher, Jong-Myoung Kim, Priya DasSarma, Ram Karan, \\ Photini Sinnis, and Shiladitya DasSarma
}

\section{Introduction}

As an innovative platform for antigen display and vaccine development, we are employing an extremophilic microbe, Halobacterium sp. NRC-1, that provides a number of advantages for production of antigenic proteins and vaccines (DasSarma 2007; DasSarma et al. 2013). This member of the archaeal domain has been

\footnotetext{
W.T. Pecher

Department of Microbiology and Immunology, University of Maryland

School of Medicine, Baltimore, MD, USA

Institute of Marine and Environmental Technology, University System of Maryland, Baltimore, MD, USA

College of Arts and Sciences, University of Baltimore, Baltimore, MD, USA

J.-M. Kim

Department of Microbiology and Immunology, University of Maryland

School of Medicine, Baltimore, MD, USA

Institute of Marine and Environmental Technology, University System of Maryland, Baltimore, MD, USA

Department of Marine Bio-Materials and Aquaculture, PuKyong National University, Pusan, Republic of Korea

P. DasSarma • R. Karan • S. DasSarma $(\bowtie)$

Department of Microbiology and Immunology, University of Maryland

School of Medicine, Baltimore, MD, USA

Institute of Marine and Environmental Technology, University System of Maryland,

Baltimore, MD, USA

e-mail: sdassarma@som.umaryland.edu

P. Sinnis

Department of Molecular Microbiology and Immunology, Bloomberg

School of Public Health, Johns Hopkins University, Baltimore, MD, USA
} 
determined to be non-toxic, lipopolysaccharide (LPS) free, and is biocompatible by virtue of its presence as a natural component of salt and salty condiments (http://www.els.net/WileyCDA/ElsArticle/refId-a0000394.html). The genome is completely sequenced and its biology has been studied in detail using genetic, transcriptomic, and proteomic methodologies (Berquist et al. 2006; DasSarma 2004; Ng et al. 1998, 2000). High-level regulated promoters have been used to develop expression vectors for the production of native and foreign proteins (Karan et al. 2013, 2014). Moreover, with Halobacterium sp., hypotonic conditions may be used to lyse cells and release expressed proteins in a stable form.

One of the most interesting applications of the Halobacterium sp. NRC-1 expression system is the display of antigenic protein arrays on nanoparticles called gas vesicles (GVNPs), that are about $300 \mathrm{~nm}$ long, lemon-shaped buoyant organelles used by cells for flotation and are both bioengineerable and highly adjuvanting (DasSarma and Arora 1997; DasSarma et al. 2013; Stuart et al. 2001, 2004). GVNPs are composed only of proteins, one of which $(\mathrm{GvpC})$ can be used for fusion to foreign antigenic proteins for display on the external surface of the nanoparticle. GVNPs have been shown to successfully display SIV, Chlamydia, and Salmonella antigens, and are processed slowly by macrophages (Childs and Webley 2012; DasSarma and DasSarma 2015; DasSarma et al. 2014; Sremac and Stuart 2008, 2010; Stuart et al. 2001, 2004). For nanoparticles displaying Salmonella SopB antigens, immunized mice were found to exhibit reduced bacterial load in organs (DasSarma et al. 2014).

Our recent interest has been to apply the Halobacterium sp. NRC-1 expression system for production of the major surface protein of sporozoites, the pre-erythrocytic form of Plasmodium falciparum which is transmitted from mosquitoes to humans. Among diseases for which there is a critical need for vaccines, malaria is one of the most widespread, with 200 million infections and over half a million deaths per year, primarily from infection by $P$. falciparum (http://who.int/malaria/publications/ world_malaria_report_2013/en/index.html). The circumsporozoite protein, or CSP, is known to be highly immunogenic and is encoded by a single-copy gene unique to Plasmodium (Nussenzweig and Nussenzweig 1989). CSP consists of an N-terminal region containing a signal sequence, a central region with multiple tetrapeptide repeats, and a C-terminal cell-adhesion domain that ends with a putative glycosylphosphatidylinositol (GPI) anchor addition sequence (Fig. 25.1) (Coppi et al. 2011; Dame et al. 1984; del Portillo et al. 1987). The number of tetrapeptide repeats may vary from 25 to 49 copies, depending on the source (Bowman et al. 2013). A subunit vaccine, RTS,S, based on P. falciparum CSP consisting of most of the C-terminal half of the protein, including 19 copies of the tetrapeptide repeat fused to the hepatitis B surface protein, has been produced in Pichia pastoris, tested in different formulations with various immunostimulatory compounds, and shown to provide partial protection. However, protection is limited in infants, and in long term immunity (Campo et al. 2014; Mo and Augustine 2014). The ultimate potential of any pre-erythrocytic vaccine is underscored by reports of sterile immunity obtained with irradiated sporozoites administered intravenously (Seder et al. 2013).

We sought to utilize the Halobacterium sp. NRC-1 expression system for production of full-length $P$. falciparum CSP. In order to maximize the production of 
parasite protein in Halobacterium sp., we designed a codon-optimized gene and cloned it into expression vectors for production of the CSP protein alone or as a fusion to the GVNPs, including the N- and C-terminal regions not present in the mature protein in Plasmodium, which may contribute to enhanced immunogenicity or immunostimulation (Kastenmüller et al. 2013; Sedegah et al. 2013). In this report, we provide evidence for the biosynthesis of full-length CSP.

\section{Materials and Methods}

\subsection{Design and Cloning of Codon-Optimized P. falciparum CSP Gene}

To design a codon-optimized P. falciparum CSP gene for expression in Halobacterium sp. NRC-1, we obtained the CSP gene sequence from the P. falciparum strain 3D7 (NCBI reference number XM_001351086.1). The codon usage table for predicted genes in the genome of Halobacterium sp. NRC-1 was used to replace rare and infrequent codons (Kennedy et al. 2001). A codon modification (AAC $>$ GGC) was incorporated in the design to add a unique KasI restriction site, which resulted in the mutation of an asparagine to glycine residue at amino acid position 201 (Fig. 25.1). The codon-optimized gene, flanked by AfeI restriction sites, was synthesized commercially for cloning into Halobacterium sp. NRC-1 expression vectors (Life Technologies, Carlsbad, CA, USA).

\subsection{Construction and Culturing of Expression Strains}

The AfeI restriction fragment coding the engineered and codon-optimized full-length CSP gene was cloned into the Halobacterium expression plasmids, pDRK and pSD, after cleavage of each at the unique $A f e I$ sites in these vectors (Karan et al. 2014). The constructed pDRKcsp6 plasmid (Fig. 25.2a) was transformed into Halobacterium sp. strain SD109 (DasSarma et al. 1988, 1995), a derivative of wild-type strain NRC-1 deleted for the active gvp gene cluster A in pNRC100 and pNRC200, to construct Halobacterium strain SD109 (pDRKcsp6). The pSDcsp20 plasmid construct (Fig. 25.2b) was also transformed into SD109 to construct Halobacterium strain SD109 (pSDcsp20). The CSP gene region of each plasmid was completely sequenced in both strands using primer walking. Halobacterium strains transformed with expression plasmids were grown in $\mathrm{CM}^{+}$media with $20 \mu \mathrm{g} / \mathrm{ml}$ mevinolin (Merck, Sharp, and Dohme, Rahway, NJ, USA). Cultures were grown at $42{ }^{\circ} \mathrm{C}$ at $220 \mathrm{rpm}$ to stationary phase. Cell lysates and GVNPs were prepared as described previously (DasSarma et al. 1995, 2013). 
CTCTTCCAGGAGTACCAGTGCTACGGCAGCAGCAGCAACACCCGCGTCCTCAACGAGCTC

$\begin{array}{llllllllllllllllllll}\text { L } & F & Q & E & Y & Q & C & Y & G & S & S & S & N & T & R & V & L & N & E & L\end{array}$

AACTACGACAACGCCGGCACCAACCTCTACAACGAGCTCGAGATGAACTACTACGGCAAG

$\begin{array}{lllllllllllllllllllll}N & Y & D & N & A & G & T & N & \text { L } & \text { Y } & \text { N } & \text { E } & \text { L } & \text { E } & \text { M } & \text { N } & \text { Y } & \text { Y } & \text { G } & \text { K }\end{array}$

CAGGAGAACTGGTACAGCCTCAAGAAGAACAGCCGCAGCCTCGGCGAGAACGACGACGGC

AACAACGAGGACAACGAGAAGCTCCGCAAGCCCAAGCACAAGAAGCTCAAGCAGCCCGCC GACCCCAACGCCAACCCCAACGTCGACCCCAACGCCAACCCCAACGCCAACCCCAACGCC $\begin{array}{llllllllllllllllllll}\text { P } & \text { P } & \text { N } & \text { A } & \text { N } & \text { P } & \text { N } & \text { V } & \text { D } & \text { P } & \text { N } & \text { A } & \text { N } & \text { P } & \text { N } & \text { A } & \text { N } & \text { P } & \text { N } & \text { A }\end{array}$ AACCCCAACGCCAACCCCAACGCCAACCCCAACGCCAACCCCAACGCCAACCCCAACGCO $\begin{array}{llllllllllllllllllll}\mathrm{N} & \mathrm{P} & \mathrm{N} & \mathrm{A} & \mathrm{N} & \mathrm{P} & \mathrm{N} & \mathrm{A} & \mathrm{N} & \mathrm{P} & \mathrm{N} & \mathrm{A} & \mathrm{N} & \mathrm{P} & \mathrm{N} & \mathrm{A} & \mathrm{N} & \mathrm{P} & \mathrm{N} & \mathrm{A}\end{array}$ AACCCCAACGCCAACCCCAACGCCAACCCCAACGCCAACCCCAACGCCAACCCCAACGCO

AACCCCAACGCCAACCCCAACGCCAACCCCAACGCCAACCCCAACGCCAACCCCAACGTC $\begin{array}{lllllllllllllllllllll}N & \mathrm{P} & \mathrm{N} & \mathrm{A} & \mathrm{N} & \mathrm{P} & \mathrm{N} & \mathrm{A} & \mathrm{N} & \mathrm{P} & \mathrm{N} & \mathrm{A} & \mathrm{N} & \mathrm{P} & \mathrm{N} & \mathrm{A} & \mathrm{N} & \mathrm{P} & \mathrm{N} & \mathrm{V}\end{array}$ KasI GACCCCGGCGCCAACCCCAACGCCAACCCCAACGCCAACCCCAACGCCAACCCCAACGCC AACCCCAACGCCAACCCCAACGCCAACCCCAACGCCAACCCCAACGCCAACCCCAACGCC

AACCCCAACGCCAACCCCAACGCCAACCCCAACGCCAACCCCAACGCCAACCCCAACGCC

AACGGCCAGGGCCACAACATGCCCAACGACCCCAACCGCAACGTCGACGAGAACGCCAAC

$\begin{array}{llllllllllllllllllllll}279 & \mathrm{~N} & \mathrm{G} & \mathrm{Q} & \mathrm{G} & \mathrm{H} & \mathrm{N} & \mathrm{M} & \mathrm{P} & \mathrm{N} & \mathrm{D} & \mathrm{P} & \mathrm{N} & \mathrm{R} & \mathrm{N} & \mathrm{V} & \mathrm{D} & \mathrm{E} & \mathrm{N} & \mathrm{A} & \mathrm{N}\end{array}$

GCCAACAGCGCCGTCAAGAACAACAACAACGAGGAGCCCAGCGACAAGCACATCAAGGAG

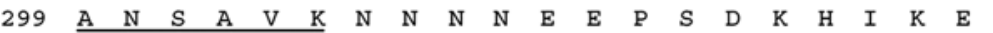

TACCTCAACAAGATCCAGAACAGCCTCAGCACCGAGTGGAGCCCCTGCAGCGTCACCTGC GGCAACGGCATCCAGGTCCGCATCAAGCCCGGCAGCGCCAACAAGCCCAAGGACGAGCTC $\begin{array}{llllllllllllllllllllll}G & N & G & I & Q & V & R & I & K & P & G & S & A & N & K & P & K & D & E & L\end{array}$ GACTACGCCAACGACATCGAGAAGAAGATCTGCAAGATGGAGAAGTG AACGTCGTCAACAGCAGCATCGGCCTCATCATGGTCCTCAGCTTCCTCTTCCTCAACTAA

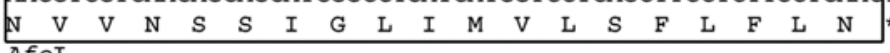

\section{$\underline{\underline{A G C G C T}}$}

Fig. 25.1 Sequence of the synthetic codon-optimized $P$. falciparum CSP gene for expression in Halobacterium sp. and translation product. AfeI and KasI restriction sites are shown with recognition sequences double-underlined. Tryptic peptides of CSP identified by LC-MS/MS analysis are underlined. The signal peptide, tetrapeptide repeats, and the putative GPI anchor are boxed 

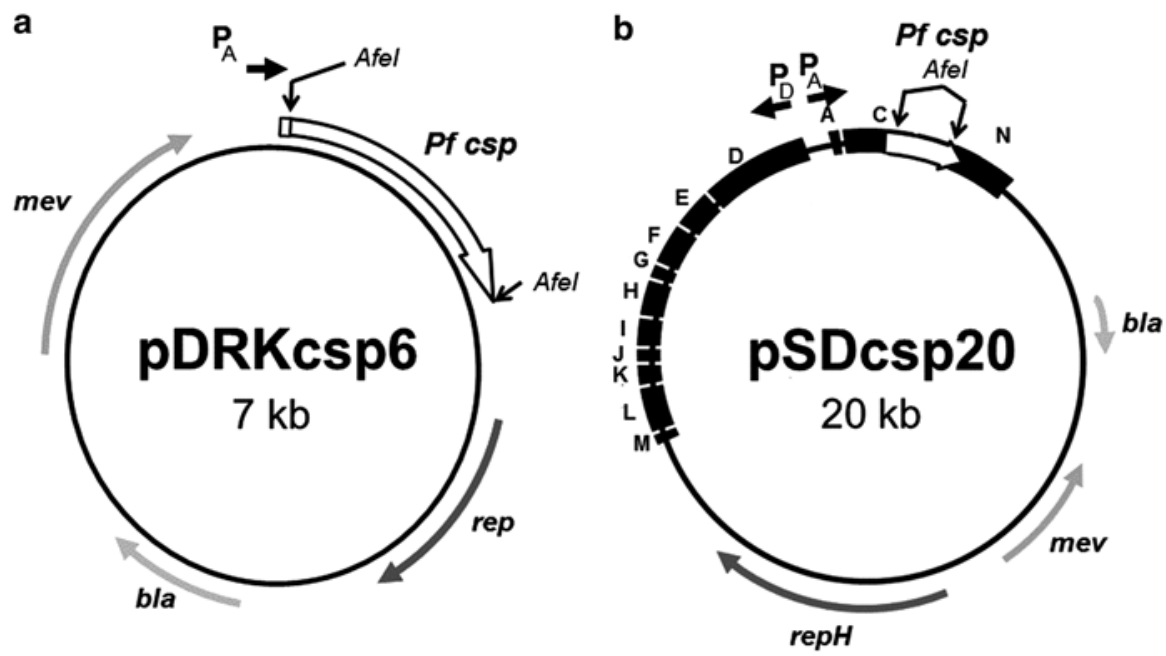

Fig. 25.2 P. falciparum CSP expression vectors pDRKcsp6 (a) and pSDcsp20 (b). The synthetic gene coding $P$. falciparum CSP (labeled $P f(s p$ ) is shown by wide white arrows between AfeI restriction sites used for cloning. Location of promoters are indicated by narrow black arrows. Locations of selection markers for mevinolin resistance (mev) and $\beta$-lactamase (bla) are shown as narrow gray arrows, as are locations of replicase genes (rep, repH). Location of the hexa-histidine tag is indicated by a small white box at the 5'-end of the CSP gene in pDRKcsp6 and locations of gvpACN and gvpDEFGHIJKLM genes are shown by black boxes in pSDcsp20

\subsection{Western Blotting Analysis}

Western blotting was carried out as previously described (Shukla and DasSarma 2004). Briefly, preparations of cell lysates were electrophoresed on $9 \%$ or $12 \%$ polyacrylamide-SDS gels. Proteins were transferred to $0.45 \mu \mathrm{m}$ Immobilon-P polyvinylidene difluoride (PVDF) membranes (Millipore Corp., Boston, MA, USA). Membranes were blocked with PTM buffer (PBS, $0.1 \%$ Tween 20, $5 \%$ nonfat dry milk), followed by overnight incubation at $4{ }^{\circ} \mathrm{C}$ after addition of the CSP-specific monoclonal antibody 2A10 (1:1,000 dilution) (Wirtz et al. 1987). Membranes were washed with PTM buffer, and incubated with rabbit anti-mouse secondary antibodies (1:2,500 dilution) labeled with alkaline phosphatase (Sigma Aldrich, St. Louis, MO, USA). For detection of immunoreactive proteins, membranes were incubated in 1-Step NBT/BCIP substrate per manufacturer's specifications (Thermo Fisher Scientific, Rockford, IL, USA). Bands were quantified by densitometry using Image J (http://imagej.nih.gov/ij/). 


\subsection{Proteomic Analysis}

To identify CSP by LC-MS/MS analysis, Halobacterium proteins were reduced with DTT, alkylated with iodoacetamide, and subsequently proteolyzed with trypsin (Shevchenko et al. 1996). Digested peptides were desalted by C18 stage-tip and eluted with $0.1 \%$ trifluoroacetic acid in $60 \%$ acetonitrile and resuspended in $0.1 \%$ formic acid for LC-MS/MS analysis. Identification of peptides was performed on a Q-Exactive instrument (Thermo Scientific, Rockford, IL, USA) interfaced with a Proxionnano flow LC system. Peptide sequences were identified from isotopically resolved masses in MS and MS/MS spectra extracted with and without deconvolution using a Thermo Scientific MS2 processor and Xtract software. MS/MS spectra were searched against protein databases using the Sequest search engine interfaced with Proteome Discoverer 1.4 software.

\section{Results}

\subsection{Construction of Halobacterium sp. Expression Strains Containing the Codon-Optimized P. falciparum CSP Gene}

Due to the great difference in GC-composition between $P$. falciparum and Halobacterium sp., (19\% versus $66 \%$ GC, respectively), we designed a synthetic CSP gene for expression in Halobacterium using the codon usage data from the genome of the wild-type NRC-1 strain (Fig. 25.1). The synthetic gene design contained $62.3 \%$ GC, incorporating the full-length CSP coding region from $P$. falciparum strain 3D7, including the $\mathrm{N}$-terminal signal and $\mathrm{C}$-terminal anchor sequence, and was flanked by AfeI restriction sites for cloning.

For construction of expression plasmids, the synthetic CSP gene was inserted into plasmid pDRK at an AfeI site downstream of the gvpA promoter, resulting in plasmid pDRKcsp6 (Fig. 25.2a). The CSP encoded by pDRKcsp6 has an N-terminal 15 amino acid residue extension (MHHHHHHLKRLPRSA) containing a hexa-histidine tag, followed by the 397 amino acid residue full-length CSP (Fig. 25.1). The synthetic CSP gene was also cloned into expression plasmid pSD at the $A f e I$ site in $g v p C$ for expression of CSP and display on GVNPs in Halobacterium (Fig. 25.2b). The resulting pSDcsp20 encodes a fusion protein with 293 amino acids of GvpC followed by the full-length CSP.

\subsection{Expression of Full-Length P. falciparum CSP in Halobacterium sp.}

The expression plasmids, pDRKcsp6 and pSDcsp20, were transformed into Halobacterium sp. strain SD109, a gas vesicle-deficient mutant of the wild-type strain. Cultures were grown to stationary phase, collected by centrifugation, and lysed 


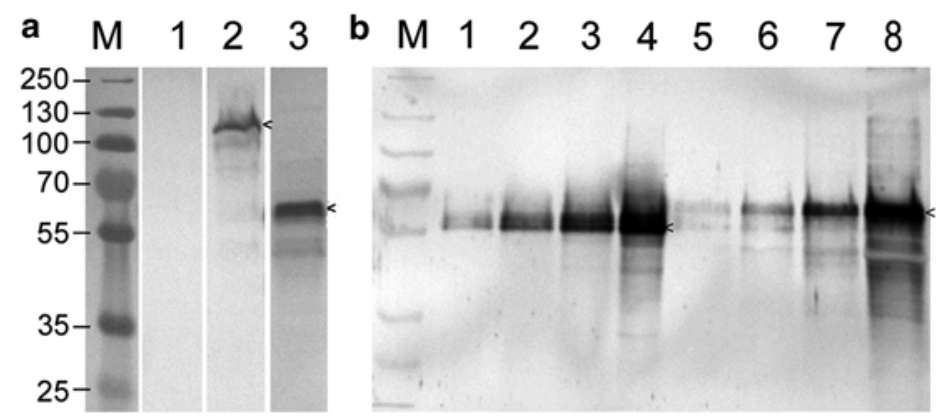

Fig. 25.3 Western blotting analysis of CSP expression strains. Halobacterium sp. SD109, SD109 (pSDcsp20), and SD109 (pDRKcsp6) (a, lanes 1-3, respectively) and P. falciparum sporozoite lysates (b, lanes 1-4, 1.9 $\times 10^{2}, 7.5 \times 10^{2}, 3 \times 10^{3}$, and $1.2 \times 10^{4}$ cells, respectively) and Halobacterium sp. SD109 (pDRKcsp6) lysates (b, lanes $5-8,8 \times 10^{4}, 3 \times 10^{5}, 1.3 \times 10^{6}$, and $5 \times 10^{6}$ cells, respectively), probed using the CSP monoclonal antibody 2A10. Lanes M contain molecular weight markers, with sizes indicated in $\mathrm{kDa}$. Arrowheads indicate the prominent CSP band

using hypotonic conditions. Growth rates of the transformants were comparable to that of the parental strain (data not shown). Cell lysates were fractionated by polyacrylamide gel electrophoresis, transferred, and probed using the CSP monoclonal antibody 2A10. Protein bands corresponding to CSP at the expected positions, $120 \mathrm{kDa}$ for strain SD109 (pSDcsp20) and $60 \mathrm{kDa}$ for strain SD109 (pDRKcsp6), were found (Fig. 25.3a). Proteins of the Halobacterium sp. SD109 (pDRKcsp6) were also subjected to trypsin digestion followed by LC-MS/MS. Five unique peptides corresponding to $P$. falciparum CSP were observed, confirming the identity of the expressed protein (Fig. 25.1). The peptides identified covered 64/397 amino acids or $16 \%$ of CSP; it should be noted that the entire tetrapeptide repeat region is devoid of trypsin sites and would not be expected to be detected by this method.

We determined the level of production of CSP in Halobacterium sp. by Western blotting analysis using $P$. falciparum sporozoite lysates as standards. Sporozoites were prepared from disrupted salivary glands of Anopheles stephensi adult females. Measured numbers of $P$. falciparum sporozoites and Halobacterium sp. SD109 (pDRKcsp6) cells were lysed, fractionated by SDS-PAGE, transferred, and probed with the CSP monoclonal antibody 2A10 (Fig. 25.3b). The CSP band in the sporozoites was observed at $55 \mathrm{kDa}$ (lanes 1-4), while the free CSP band in Halobacterium was observed at $60 \mathrm{kDa}$ (lanes 5-8), which is larger due to the presence of the signal sequence, the putative GPI anchor, and the hexa-histidine tag. Based on the intensity of these major bands apparent in the Western blot, we determined that $10^{3} \mathrm{P}$. falciparum sporozoites produce similar quantities of CSP as $8.3 \times 10^{5}$ Halobacterium sp. SD109 (pDRKcsp6) cells. This level of expression represents $3.3 \mathrm{mg}$ of free CSP per liter Halobacterium culture. The level of CSP fusion protein for display on GVNPs, observed as a $120 \mathrm{kDa}$ protein, corresponds to about $15 \%$ of this amount or $0.5 \mathrm{mg}$ of CSP per liter of culture (Fig 25.3a and data not shown). 


\section{Discussion}

Using the Archaeal expression host Halobacterium sp. NRC-1, we have documented the expression of full-length $P$. falciparum CSP. This extremophilic expression system provides a yield of CSP sufficient for immunological studies and the potential for vaccine development. Additional benefits include biocompatibility, non-toxicity, lack of LPS, and potential for scaling. Another significant advantage is that the cells are easily disrupted by hypotonic conditions, releasing the content without the need for mechanical or enzymatic processes. The Halobacterium sp. cells contain large quantities of intracellular GVNPs, which have been shown to be highly adjuvanting, eliciting strong and long-lived immune responses (Childs and Webley 2012; DasSarma and DasSarma 2015; DasSarma et al. 2013, 2014; Sremac and Stuart 2008, 2010; Stuart et al. 2001, 2004). The expression system permits CSP to be produced freely or potentially bound and displayed as an ordered array on the GVNPs. The CSP protein produced in Halobacterium is recognized by the 2A10 CSP monoclonal antibody, indicating that its antigenicity is retained in this host. These results may allow the development of multiple formulations for immunological testing and vaccine development in the future.

CSP sequences are available from diverse Plasmodium strains and several have been previously expressed in Escherichia coli, P. pastoris, yeast and other organisms (Dame et al. 1984; Kastenmüller et al. 2013; Kolodny et al. 2001; Plassmeyer et al. 2009; Young et al. 1985). However, in nearly all of these cases, successful expression has employed truncated forms of CSP lacking either the N-terminal signal peptide, the C-terminal putative GPI anchor regions, or both. Early attempts to generate full-length CSP in E. coli resulted in the expression of unstable products at low levels (Young et al. 1985). In our case, the entire CSP molecule, either free or fused to $\mathrm{GvpC}$, is produced in Halobacterium sp. The presence of significant quantities of the entire CSP molecule offers a potentially attractive alternative to the other expression systems.

In a recent study, near full-length CSP (lacking the signal sequence and putative GPI anchor sequence) was shown to elicit a stronger antibody reaction in mice and non-human primates compared to the RTS,S vaccine that lacks the entire N-terminus of the CSP (Kastenmüller et al. 2013). Adjuvants were shown to differentially mediate effects on antibody and Th1 immunity as well as CD4+ T cell immunity and protection in mice. Haloarchaeal GVNPs may provide a significant boost to immune responses against displayed antigens, as suggested when Salmonella SopB antigen-GVNPs successfully reduced bacterial burden upon administration with live attenuated bacteria after challenge (DasSarma et al. 2014). Immunostimulatory effects of SopB-GVNPs were confirmed by significant increases in levels of IFN- $\gamma$, IL-2, and IL-9 in immunized mice.

The additional sequences present in full-length CSP produced in Halobacterium sp. that are lacking in the mature sporozoite CSP may potentially be either immunogenic or immunostimulatory in ways not observed with the truncated proteins. Consistent with this notion, the signal peptide of CSP contains epitopes recognized 
by CD8+ T cells of individuals from malaria endemic areas (Sedegah et al. 2013). Moreover, a combination of cell mediated (i.e. CD4+ Th1, CD8+ T cell) and humoral responses have been shown to be critical to provide protective immunity (Ménard et al. 2013; Schofield et al. 1987). Additional studies are necessary to determine the immunogenic effects of the full-length CSP produced in Halobacterium free or displayed on GVNPs.

The biocompatibility of the Halobacterium cells and GVNPs represents another significant distinguishing feature of this system (DasSarma et al. 2010). Furthermore, antigens fused to GNVPs were reported to be stable without refrigeration in Halobacterium cells for extended periods of time, suggesting that this platform is a valuable alternative for vaccines targeting diseases in developing countries (DasSarma et al. 2010, 2014). Although the ability to partially purify GVNPs by flotation may be valuable, the potential for direct use of CSP-containing cells or cell lysates can also be pursued and may offer advantages for immunogenicity. However, since in some cases, hexa-histidine tagged $\mathrm{N}$-termini could facilitate purification of expressed proteins in other hosts, the inclusion of this affinity tag may be utilized, should purification be desired (Kolodny et al. 2001; Plassmeyer et al. 2009). Finally, the Halobacterium sp. CSP expression system may also be modified to express variant proteins, including shorter or truncated forms, should those become needed in future.

Conflict of Interest Wolf T. Pecher, Jong-Myoung Kim, Priya DasSarma, Ram Karan, Photini Sinnis, and Shiladitya DasSarma declare that they have no conflict of interest.

Acknowledgments This work was supported by Bill \& Melinda Gates Foundation grant OPP1061509, and National Institutes of Health grant R03 AI107634 to SD and National Institutes of Health grant R01 AI056840 to PS. JK was supported by the PKNU Research Abroad Fund CD-20130914. We thank Susan Barnes and Folasade Ekulona for technical assistance, Stefanie Trop and Peter Dumoulin for valuable discussions, and Prof. F. Zavala for critical reading of the manuscript.

\section{References}

Berquist BR, Müller JA, DasSarma S (2006) Chapter 27. Genetic systems for halophilic archaea. In: Oren A, Rainey F (eds) Methods in microbiology, vol 35. Elsevier/Academic Press, Amsterdam, pp 649-680

Bowman NM, Congdon S, Mvalo T, Patel JC, Escamilla V, Emch M, Martinson F, Hoffman I, Meshnick SR, Juliano JJ (2013) Comparative population structure of Plasmodium falciparum circumsporozoite protein NANP repeat lengths in Lilongwe, Malawi. Sci Rep 3:1990

Campo JJ, Sacarlal J, Aponte JJ, Aide P, Nhabomba AJ, Dobaño C, Alonso PL (2014) Duration of vaccine efficacy against malaria: 5 th year of follow-up in children vaccinated with RTS, S/AS02 in Mozambique. Vaccine 32(19):2209-2216. doi:10.1016/j.vaccine.2014.02.042

Childs TS, Webley WC (2012) In vitro assessment of halobacterial gas vesicles as a Chlamydia vaccine display and delivery system. Vaccine 30(41):5942-5948

Coppi A, Natarajan R, Pradel G, Bennett BL, James ER, Roggero MA, Corradin G, Persson C, Tewari R, Sinnis P (2011) The malaria circumsporozoite protein has two functional domains, each with distinct roles as sporozoites journey from mosquito to mammalian host. J Exp Med 208(2):341-356 
Dame JB, Williams JL, McCutchan TF, Weber JL, Wirtz RA, Hockmeyer WT, Maloy WL, Haynes JD, Schneider I, Roberts D, Sanders GS, Reddy EP, Diggs CL, Miller LH (1984) Structure of the gene encoding the immunodominant surface antigen on the sporozoite of the human malaria parasite Plasmodium falciparum. Science 225(4662):593-599

DasSarma S (2004) Genome sequence of an extremely halophilic archaeon. In: Fraser CM, Read T, Nelson KE (eds) Microbial genomes. Humana Press, Totowa, pp 383-399

DasSarma S (2007) Extreme microbes: the salty side of life. Am Sci 95(3):224-231

DasSarma S, Arora P (1997) Genetic analysis of the gas vesicle gene cluster in haloarchaea. FEMS Microbiol Lett 153(1):1-10

DasSarma S, DasSarma P (2015) Gas vesicle nanoparticles for antigen display. Vaccines 3(3):686-702

DasSarma S, Halladay JT, Jones JG, Donovan JW, Giannasca PJ, Tandeau de Marsac N (1988) High-frequency mutations in a plasmid-encoded gas vesicle gene in Halobacterium halobium. Proc Natl Acad Sci U S A 85(18):6861-6865

DasSarma S, Robb FT, Place AR, Sowers KR, Schreier HJ, Fleischmann EM (eds) (1995) Archaea: a laboratory manual - halophiles. Cold Spring Harbor Laboratory Press, Plainview

DasSarma P, Coker JA, Huse V, DasSarma S (2010) Halophiles, industrial applications. In: Flickinger MC (ed) Encyclopedia of industrial biotechnology: bioprocess, bioseparation, and cell technology. Wiley, Hoboken, pp 1-43

DasSarma S, Karan R, DasSarma P, Barnes S, Ekulona F, Smith B (2013) An improved genetic system for bioengineering buoyant gas vesicle nanoparticles from haloarchaea. BMC Biotechnol 13:112. doi:10.1186/1472-6750-13-112

DasSarma P, Negi VD, Balakrishnan A, Karan R, Barnes S, Ekulona F, Chakravortty D, DasSarma S (2014) Haloarchaeal gas vesicle nanoparticles displaying Salmonella SopB antigen reduce bacterial burden when administered with live attenuated bacteria. Vaccine 32(35):4543-4549

del Portillo HA, Nussenzweig RS, Enea V (1987) Circumsporozoite gene of a Plasmodium falciparum strain from Thailand. Mol Biochem Parasitol 24(3):289-294

Karan R, Capes MD, DasSarma P, DasSarma S (2013) Cloning, overexpression, purification, and characterization of a polyextremophilic $\beta$-galactosidase from the Antarctic haloarchaeon Halorubrum lacusprofundi. BMC Biotechnol 13:3. doi:10.1186/1472-6750-13-3

Karan R, DasSarma P, Balcer-Kubiczek E, Weng RR, Liao C-C, Goodlett DR, Ng WV, DasSarma S (2014) Bioengineering radioresistance by overproduction of RPA, a mammalian-type singlestranded DNA-binding protein, in a halophilic archaeon. Appl Microbiol Biotechnol 98(4): $1737-1747$

Kastenmüller K, Espinosa DA, Trager L, Stoyanov C, Salazar AM, Pokalwar S, Singh S, Dutta S, Ockenhouse CF, Zavala F, Seder RA (2013) Full-length Plasmodium falciparum circumsporozoite protein administered with long-chain poly $(\mathrm{I} \cdot \mathrm{C})$ or the Toll-like receptor 4 agonist glucopyranosyl lipid adjuvant-stable emulsion elicits potent antibody and CD4+ T cell immunity and protection in mice. Infect Immun 81(3):789-800

Kennedy SP, Ng WV, Salzberg SL, Hood L, DasSarma S (2001) Understanding the adaptation of Halobacterium species NRC-1 to its extreme environment through computational analysis of its genome sequence. Genome Res 11:1641-1650

Kolodny N, Kitov S, Vassell MA, Miller VL, Ware LA, Fegeding K, De La Vega P, Sacci JB Jr, Lanar DE (2001) Two-step chromatographic purification of recombinant Plasmodium falciparum circumsporozoite protein from Escherichia coli. J Chromatogr B Biomed Sci Appl 762(1):77-86

Ménard R, Tavares J, Cockburn I, Markus M, Zavala F, Amino R (2013) Looking under the skin: the first steps in malarial infection and immunity. Nat Rev Microbiol 11(10):701-712

Mo AX, Augustine AD (2014) NIAID meeting report: improving malaria vaccine strategies through the application of immunological principles. Vaccine 32(10):1132-1138

$\mathrm{Ng}$ WV, Ciufo SA, Smith TM, Bumgarner RE, Baskin D, Faust J, Hall B, Loretza C, Seto J, Slagel J, Hood L, DasSarma S (1998) Snapshot of a large dynamic replicon in a halophilic archaeon: megaplasmid or minichromosome? Genome Res 8:1131-1141 
Ng WV, Kennedy SP, Mahairas GG, Berquist B, Pan M, Shukla HD, Lasky SR, Baliga NS, Thorsson V, Sbrogna J, Swartzell S, Weir D, Hall J, Dahl TA, Welti R, Goo YA, Leithauser B, Keller K, Cruz R, Danson MJ, Hough DW, Maddocks DG, Jablonski PE, Krebs MP, Angevine CM, Dale H, Isenbarger TA, Peck RF, Pohlschroder M, Spudich JL, Jung K-H, Alam M, Freitas T, Hou S, Daniels CJ, Dennis PP, Omer AD, Ebhardt H, Lowe TM, Liang P, Riley M, Hood L, DasSarma S (2000) Genome sequence of Halobacterium species NRC-1. Proc Natl Acad Sci U S A 97(22):12176-12181

Nussenzweig V, Nussenzweig RS (1989) Rationale for the development of an engineered sporozoite malaria vaccine. Adv Immunol 45:283-334

Plassmeyer ML, Reiter K, Shimp RL Jr, Kotova S, Smith PD, Hurt DE, House B, Zou X, Zhang Y, Hickman M, Uchime O, Herrera R, Nguyen V, Glen J, Lebowitz J, Jin AJ, Miller LH, MacDonald NJ, Wu Y, Narum DL (2009) Structure of the Plasmodium falciparum circumsporozoite protein, a leading malaria vaccine candidate. J Biol Chem 284:26951-26963

Schofield L, Villaquiran J, Ferreira A, Schellekens H, Nussenzweig R, Nussenzweig V (1987) $\gamma$ interferon, CD8+ T cells and antibodies required for immunity to malaria sporozoites. Nature 330(6149):664-666

Sedegah M, Kim Y, Ganeshan H, Huang J, Belmonte M, Abot E, Banania JG, Farooq F, McGrath S, Peters B, Sette A, Soisson L, Diggs C, Doolan D, Tamminga C, Villasante E, Hollingdale MR, Richie T (2013) Identification of minimal human MHC-restricted CD8+ T-cell epitopes within the Plasmodium falciparum circumsporozoite protein (CSP). Malar J 12:185

Seder RA, Chang LJ, Enama ME, Zephir KL, Sarwar UN, Gordon IJ, Holman LA, James ER, Billingsley PF, Gunasekera A, Richman A, Chakravarty S, Manoj A, Velmurugan S, Li ML, Ruben AJ, Li T, Eappen AG, Stafford RE, Plummer SH, Hendel CS, Novik L, Costner PJM, Mendoza FH, Saunders JG, Nason MC, Richardson JH, Murphy J, Davidson SA, Richie T, Sedegah M, Sutamihardja A, Fahle GA, Lyke KE, Laurens MB, Roeder M, Tewari K, Epstein JE, Sim BKL, Ledgerwood JE, Graham BS, Hoffman SL, the VRC 312 Study Team (2013) Protection against malaria by intravenous immunization with a nonreplicating sporozoite vaccine. Science 341(6152):1359-1365

Shevchenko A, Wilm M, Vorm O, Mann M (1996) Mass spectrometric sequencing of proteins silver-stained polyacrylamide gels. Anal Chem 68(5):850-858

Shukla HD, DasSarma S (2004) Complexity of gas vesicle biogenesis in Halobacterium sp. strain NRC-1: identification of five new proteins. J Bacteriol 186(10):3182-3186

Sremac M, Stuart ES (2008) Recombinant gas vesicles from Halobacterium sp. displaying SIV peptides demonstrate biotechnology potential as a pathogen peptide delivery vehicle. BMC Biotechnol 8:9

Sremac M, Stuart ES (2010) SIVsm Tat, Rev, and Nef1: functional characteristics of r-GV internalization on isotypes, cytokines, and intracellular degradation. BMC Biotechnol 10:54

Stuart ES, Sremac M, Morshed F, DasSarma S (2001) Antigen presentation using novel particulate organelles from halophilic archaea. J Biotechnol 88(2):119-128

Stuart ES, Morshed F, Sremac M, DasSarma S (2004) Cassette-based presentation of SIV epitopes with recombinant gas vesicles from halophilic archaea. J Biotechnol 114(3):225-237

Wirtz RA, Zavala F, Charoenvit Y, Campbell GH, Burkot TR, Schneider I, Esser KM, Beaudoin RL, Andre RG (1987) Comparative testing of monoclonal antibodies against Plasmodium falciparum sporozoites for ELISA development. Bull World Health Organ 65(1):39-45

Young JF, Hockmeyer WT, Gross M, Ballou WR, Wirtz RA, Trosper JH, Beaudoin RL, Hollingdale MR, Miller LH, Diggs CL, Rosenberg M (1985) Expression of Plasmodium falciparum circumsporozoite proteins in Escherichia coli for potential use in a human malaria vaccine. Science 228(4702):958-962 